\title{
How to Write the Introduction to a Scientific Paper?
}

\begin{abstract}
I once had a professor tell a class that he sifted through our pile of essays, glancing at the titles and introductions, looking for something that grabbed his attention. Everything else went to the bottom of the pile to be read last, when he was tired and probably grumpy from all the marking. Don't get put at the bottom of the pile, he said.
\end{abstract}

Anonymous

\subsection{What is the Importance of an Introduction?}

An Introduction to a scientific paper familiarizes the reader with the background of the issue at hand. It must reflect why the issue is topical and its current importance in the vast sea of research being done globally. It lays the foundation of biomedical writing and is the first portion of an article according to the IMRAD pattern (Introduction, Methodology, Results, and Discussion) [1].

It provides the flavour of the article and many authors have used phrases to describe it for example-'like a gate of the city' [2], 'the beginning is half of the whole' [3], 'an introduction is not just wrestling with words to fit the facts, but it also strongly modulated by perception of the anticipated reactions of peer colleagues', [4] and 'an introduction is like the trailer to a movie'. A good introduction helps captivate the reader early. 


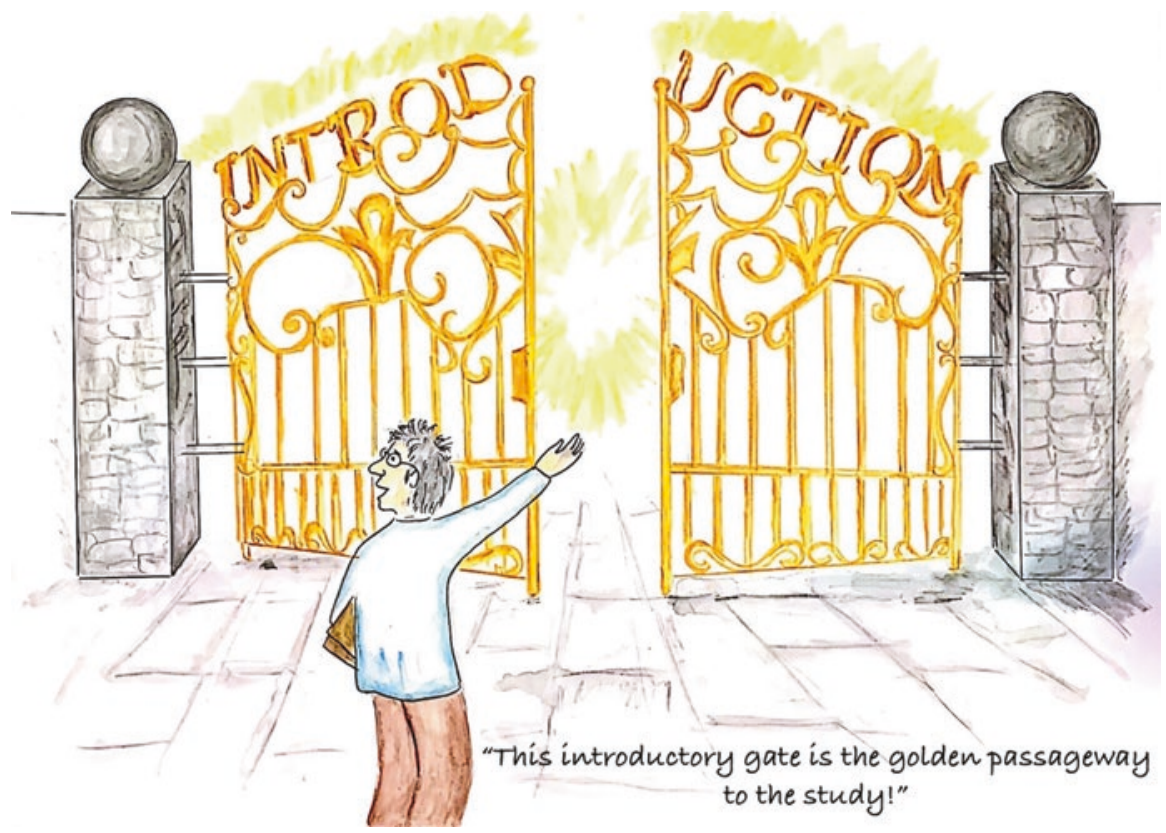

\subsection{What Are the Principles of Writing a Good Introduction?}

A good introduction will 'sell' an article to a journal editor, reviewer, and finally to a reader [3]. It should contain the following information [5, 6]:

- The known-The background scientific data

- The unknown-Gaps in the current knowledge

- Research hypothesis or question

- Methodologies used for the study

The known consist of citations from a review of the literature whereas the unknown is the new work to be undertaken. This part should address how your work is the required missing piece of the puzzle.

\subsection{What Are the Models of Writing an Introduction?}

These are:

1. The Problem-solving model 
First described by Swales et al. in 1979, in this model the writer should identify the 'problem' in the research, address the 'solution' and also write about 'the criteria for evaluating the problem' $[7,8]$.

2. The CARS model that stands for Creating A Research Space $[9,10]$.

The two important components of this model are:

- Establishing a territory (situation)

- Establishing a niche (problem)

- Occupying a niche (the solution)

In this popular model, one can add a fourth point, i.e., a conclusion [10].

\subsection{What Is Establishing a Territory?}

This includes: [9]

- Stating the general topic and providing some background about it.

- Providing a brief and relevant review of the literature related to the topic.

- Adding a paragraph on the scope of the topic including the need for your study.

\subsection{What Is Establishing a Niche?}

Establishing a niche includes:

- Stating the importance of the problem.

- Outlining the current situation regarding the problem citing both global and national data.

- Evaluating the current situation (advantages/ disadvantages).

- Identifying the gaps.

- Emphasizing the importance of the proposed research and how the gaps will be addressed.

- Stating the research problem/ questions.

- Stating the hypotheses briefly.

Figure 17.1 depicts how the introduction needs to be written. A scientific paper should have an introduction in the form of an inverted pyramid. The writer should start with the general information about the topic and subsequently narrow it down to the specific topic-related introduction. 

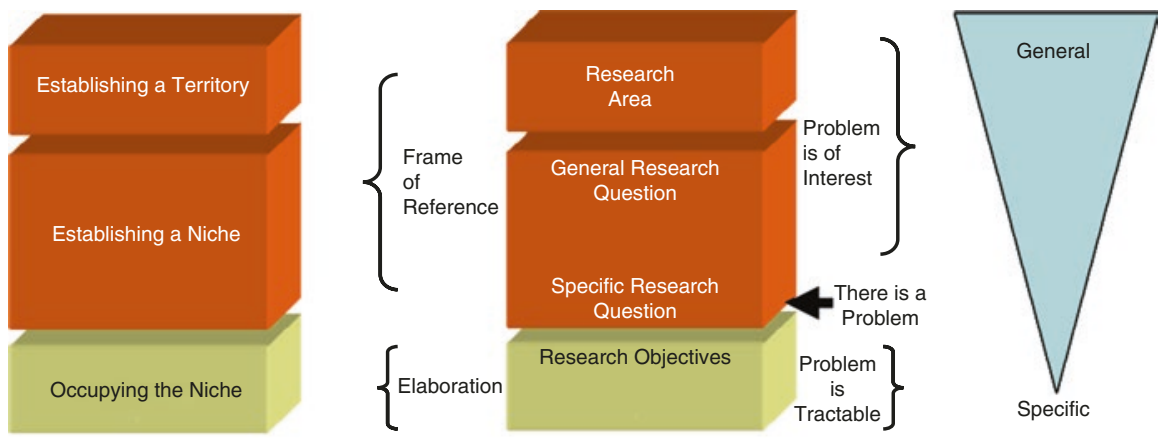

Fig. 17.1 Flow of ideas from the general to the specific

\subsection{What Does Occupying a Niche Mean?}

This is the third portion of the introduction and defines the rationale of the research and states the research question. If this is missing the reviewers will not understand the logic for publication and is a common reason for rejection $[11,12]$. An example of this is given below:

Till date, no study has been done to see the effectiveness of a mesh alone or the effectiveness of double suturing along with a mesh in the closure of an umbilical hernia regarding the incidence of failure. So, the present study is aimed at comparing the effectiveness of a mesh alone versus the double suturing technique along with a mesh.

\subsection{How Long Should the Introduction Be?}

For a project protocol, the introduction should be about 1-2 pages long and for a thesis it should be 3-5 pages in a double-spaced typed setting. For a scientific paper it should be less than $10-15 \%$ of the total length of the manuscript $[13,14]$.

\subsection{How Many References Should an Introduction Have?}

All sections in a scientific manuscript except the conclusion should contain references. It has been suggested that an introduction should have four or five or at the most one-third of the references in the whole paper [15]. 


\subsection{What Are the Important Points Which Should be not Missed in an Introduction?}

An introduction paves the way forward for the subsequent sections of the article. Frequently well-planned studies are rejected by journals during review because of the simple reason that the authors failed to clarify the data in this section to justify the study $[16,17]$. Thus, the existing gap in knowledge should be clearly brought out in this section (Fig. 17.2).

The following points are important to consider:

- The introduction should be written in simple sentences and in the present tense.

- Many of the terms will be introduced in this section for the first time and these will require abbreviations to be used later.

- The references in this section should be to papers published in quality journals (e.g., having a high impact factor).

- The aims, problems, and hypotheses should be clearly mentioned.

- Start with a generalization on the topic and go on to specific information relevant to your research.

Fig. 17.2 How should the abstract, introduction, and discussion look

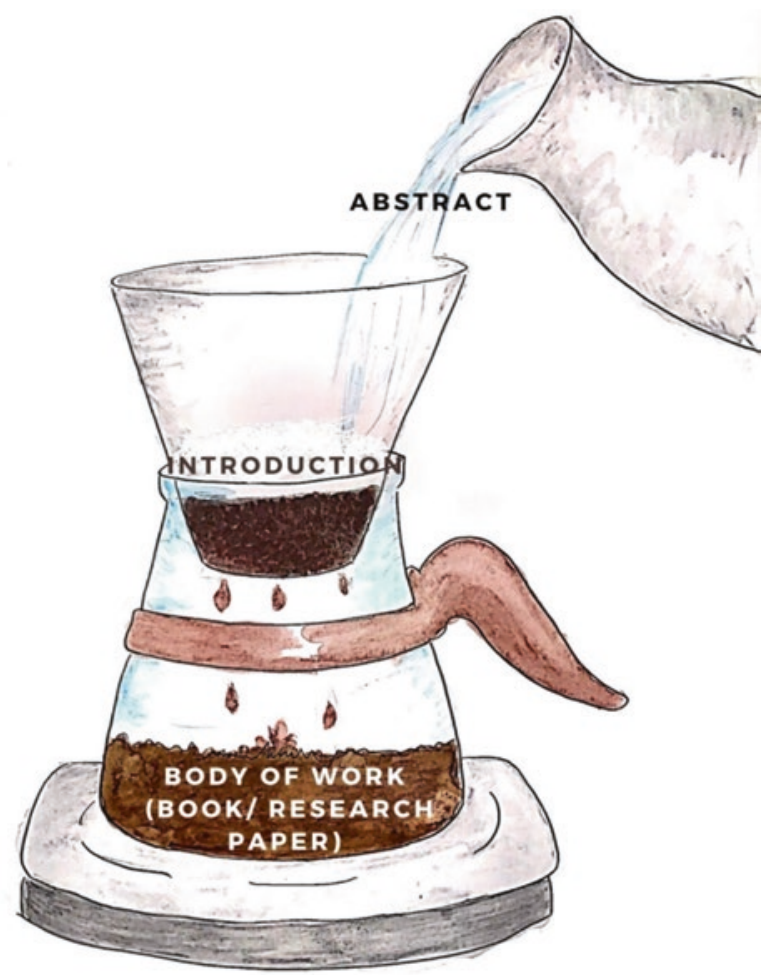




\subsection{Example of an Introduction}

\section{Stratification of Risk Groups for Developing Diabetes among Healthy Non-Diabetic Population using Skin Autofluoroscence Spectroscopic Screening (From editor CMRP with permission)}

Introduction

The prevalence of diabetes in India has remained at $11.8 \%$ in the last four years, according to the National Diabetes and Diabetic Retinopathy Survey report released by the health and family welfare ministry. [1] The chronic hyperglycaemia in diabetes is associated ytth longterm complications like retinopathy, nephropathy and neuropathy. Multiple pathógenic processes are involved in the development of diabetes, these range from autoimmune destruction of the pancreatic $\beta$-cells with subsequent insulin deficiency to abnormalities that resultin resistance to the physiological action of insulin. [2]

The autofluorescence (AF) is a widespread phenomenon which operates due to the presence of intrinsic biomolecules acting as endogenous fluorophores in the tissues of the human body. The relationship of these endogenous fluorophores with morpho-functional properties of the body, which are influencing their AF emission features, provides an outstandingly powerful resource for the direct monitoring of the biological substrate condition. [3]

AGE estimation gives a measure of long-term cumulative metabolic stress and it acts as a mechanism for the "metabolic memory" observed in diabetes. We studied Skin Autofluoroscence Spectroscopy as a screening method for estimating subcutaneous accumulation of AGE and quantified it to analyse the risk for diabetes in a non diabetic population.

Risk of developing diabetes have been vividly studied in the past and have been defined in many studies, such as the ones by Yanling et al [4], Belloui et al [5] at international level and Occupying by $\mathrm{J}$ Aravinda [6] in India itself. The results have been more or less similar in expressing that a niche $\mathrm{BMI}$, age and family history have been significant predisposing risk factors for developing

\subsection{Conclusions}

- An Introduction is a brief account of what the study is about. It should be short, crisp, and complete.

- It has to move from a general to a specific research topic and must include the need for the present study.

- The Introduction should include data from a literature search, i.e., what is already known about this subject and progress to what we hope to add to this knowledge.

\section{References}

1. Moore A. What's in a discussion section? Exploiting 2-dimensionality in the online world. Bioassays. 2016;38(12):1185.

2. Annesley TM. The discussion section: your closing argument. Clin Chem. 2010;56(11):1671-4.

3. Bavdekar SB. Writing the discussion section: describing the significance of the study findings. J Assoc Physicians India. 2015;63(11):40-2. 
4. Foote M. The proof of the pudding: how to report results and write a good discussion. Chest. 2009;135(3):866-8.

5. Kearney MH. The discussion section tells us where we are. Res Nurs Health. 2017;40(4):289-91.

6. Ghasemi A, Bahadoran Z, Mirmiran P, Hosseinpanah F, Shiva N, Zadeh-Vakili A. The principles of biomedical scientific writing: discussion. Int J Endocrinol Metab. 2019;17(3):e95415.

7. Swales JM, Feak CB. Academic writing for graduate students: essential tasks and skills. Ann Arbor, MI: University of Michigan Press; 2004.

8. Colombo M, Bucher L, Sprenger J. Determinants of judgments of explanatory power: credibility, generality, and statistical relevance. Front Psychol. 2017;8:1430.

9. Mozayan MR, Allami H, Fazilatfar AM. Metadiscourse features in medical research articles: subdisciplinary and paradigmatic influences in English and Persian. Res Appl Ling. 2018;9(1):83-104.

10. Hyland K. Metadiscourse: mapping interactions in academic writing. Nordic J English Stud. 2010;9(2):125.

11. Hill AB. The environment and disease: association or causation? Proc Royal Soc Med. 2016;58(5):295-300.

12. Alpert JS. Practicing medicine in Plato's cave. Am J Med. 2006;119(6):455-6.

13. Walsh K. Discussing discursive discussions. Med Educ. 2016;50(12):1269-70.

14. Polit DF, Beck CT. Generalization in quantitative and qualitative research: myths and strategies. Int J Nurs Stud. 2010;47(11):1451-8.

15. Jawaid SA, Jawaid M. How to write introduction and discussion. Saudi J Anaesth. 2019;13(Suppl 1):S18-9.

16. Jawaid SA, Baig M. How to write an original article. In: Jawaid SA, Jawaid M, editors. Scientific writing: a guide to the art of medical writing and scientific publishing. Karachi: Published by Med-Print Services; 2018. p. 135-50.

17. Hall GM, editor. How to write a paper. London: BMJ Books, BMJ Publishing Group; 2003. Structure of a scientific paper. p. 1-5.

Open Access This chapter is licensed under the terms of the Creative Commons Attribution 4.0 International License (http://creativecommons.org/licenses/by/4.0/), which permits use, sharing, adaptation, distribution and reproduction in any medium or format, as long as you give appropriate credit to the original author(s) and the source, provide a link to the Creative Commons license and indicate if changes were made.

The images or other third party material in this chapter are included in the chapter's Creative Commons license, unless indicated otherwise in a credit line to the material. If material is not included in the chapter's Creative Commons license and your intended use is not permitted by statutory regulation or exceeds the permitted use, you will need to obtain permission directly from the copyright holder.

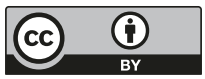

